\title{
Behavior of a new type of shear connector for U-shaped steel-concrete hybrid beams
}

\author{
Pisey $\mathrm{Keo}^{\mathrm{a}}$, Clémence Lepourry ${ }^{\mathrm{a}, \mathrm{b}}$, Hugues Somja ${ }^{\mathrm{a}, *}$, Frank Palas $^{\mathrm{b}}$ \\ ${ }^{a}$ Université Européenne de Bretagne - INSA de Rennes, LGCGM/Structural Engineering Research Group, 20 \\ avenue des Buttes de Coësmes, CS 70839, F-35708 Rennes Cedex 7, France \\ ${ }^{b}$ INGENOVA, Civil Engineering Office, 5 Rue Louis Jacques Daguerre, 35136 Saint-Jacques-de-la-Lande, France
}

\begin{abstract}
This paper presents an investigation of the behavior of a new type of shear connectors used in Ushaped steel-concrete hybrid beams. Besides the role in transferring the force between concrete and steel material, this new type of shear connectors, welded on the upper flange of the U-shaped steel beam, serves to maintain the shape of the steel cross-section during concrete encasement. Several forms of shear connectors can be used such as L-shaped or square cross-section. The experimental investigation of the behavior of these shear connectors through asymmetrical push-out tests is presented in this paper. A finite element model has been developed in order to identify the stress behavior of the connectors and the surrounding concrete. The FE model is validated by comparing its results against experimental data and then used to perform a parametric study. Based on the parametric study results, an analytical formula for calculating the force transfer capacity of the shear connector is proposed.
\end{abstract}

Keywords: Composite structure; steel-encased concrete hybrid beam; angle-shaped shear connector; square bar shear connector; push-out test

\section{Introduction}

In composite construction, profiled steel sheets have been successfully used as permanent and integral formwork for the underneath of reinforced concrete slabs [1 3]. Profiled steel sheets serve not only as a concrete formwork during construction but also as principal tensile reinforcements for bottom fibers of the composite slab, offering an economic design solution over a plywood formwork. Acting compositely with reinforced concrete slab, profiled steel sheets produce a considerably stiffer and stronger floor system than many others. Consequently, the weight and size of primary structures as well as foundations can be reduced. Over the last few years, the profiled steel sheet has been introduced as permanent formwork and integral shuttering for the sides of reinforced concrete beams [4-7]. More recently, a U-shaped steel profile with infill concrete has

\footnotetext{
${ }^{*}$ Corresponding author.

Email address: hugues.somja@insa-rennes.fr (Hugues Somja)
} 
been developed [8]. This new composite configuration can be considered as one of the most recent developments in steel-concrete composite beam construction which provides several advantages: more ductility compared to reinforced concrete beams with the same flexural strength, increase in shear strength and shear ductility, increase in span to depth ratio, reduction of concrete creep and shrinkage, and decrease in site labor costs. Although the infill concrete in the U-shaped steel profile increases the weight of the beam, it helps mitigate local buckling of the steel webs and improve strength and stiffness of the beam. In addition, fire resistance can be assessed by ensuring that the reinforced concrete beam, surrounded by the profiled steel section, can resist the fire loads.

The overall behavior of composite steel-concrete members strongly depends on shear connection between steel and concrete encasement which may be accomplished by three main shear transferring mechanisms: chemical bonding (bond between cement paste and surface of the steel), friction (assumed to be proportional to the normal force at the interface) and mechanical interaction (due to embossments, ribs or shear connectors). The role of shear connection is essential; without it there is no collaboration between steel and concrete material. It limits the slip that may occur along the steel-concrete interface. Thus, ensuring a resumption of longitudinal shear, it allows to obtain a composite section with two components working together. However, superposition of force transfer mechanisms is not generally permitted. The experimental data indicate that direct bearing or shear connection often does not initiate before the direct bond interaction has been breached. Moreover, limited experimental data is available regarding the interaction of direct bearing and shear connection via steel anchors. Therefore, the shear connection between the two materials is supposed to be ensured only by the mechanical devices, commonly headed studs. The behavior of headed stud shear connectors has been investigated by numerous researchers worldwide by conducting push-out experimental tests [9-11] and/or by numerical simulation [12 14]. Although the common type of shear connector is headed stud, some older generations of shear connectors such as channel, angle or square bar shear connectors have been increasingly interested by many researchers [15 23] over the last decade. The installation of these older generations of shear connectors is not expensive since the procedure is similar to that used for beam stiffeners or connection components, where a specific welding equipment with high voltage is not required [18]. Recently, angle connectors have been used in steel-concrete composite beams with U-shaped steel girders [8. However, no analytical models were readily available for calculating the shear force transfer capacity of this shear connector type, used in this new composite beam configuration, as yet.

In this paper, the behavior of two types of shear connector for U-shaped steel-concrete hybrid beams (USCB), see Fig. 1 is investigated. Besides the role in transferring the force between the two materials, these shear connectors, welded on the upper flange of the U-section, serve to maintain the shape of the steel cross-section during concrete encasement. Several forms of the connector cross-section can be used such as L-shaped or square cross-section. The L-shaped angle connectors, in the absence of top flange, could be cheaper and more economical compared to the channel ones. In general, a hoop reinforcement should be provided for the L-shaped angle connector while being 
used in classical composite beams, in order to limit the uplift of the concrete slab [24]. However, it is not the case for L-shaped angle connectors used in U-shaped steel-concrete hybrid beams in consideration of the connector part fully embedded in the concrete. This new type of shear connection is not covered in present norms of composite structures and it requires an investigation on its behavior and on force transfer mechanisms. This paper presents the experimental investigation of the behavior of these shear connectors through asymmetrical push-out tests. Two different types of the shear connector cross-section are considered: square and L-shaped section. To get further insight into the force transfer mechanism while using L-shaped shear connectors as connector devices in USCB, a finite element model is developed. The later is validated by comparing its results against four experimental data tests. Based on a parametric study using FE model, an analytical design formula for shear connectors is proposed.

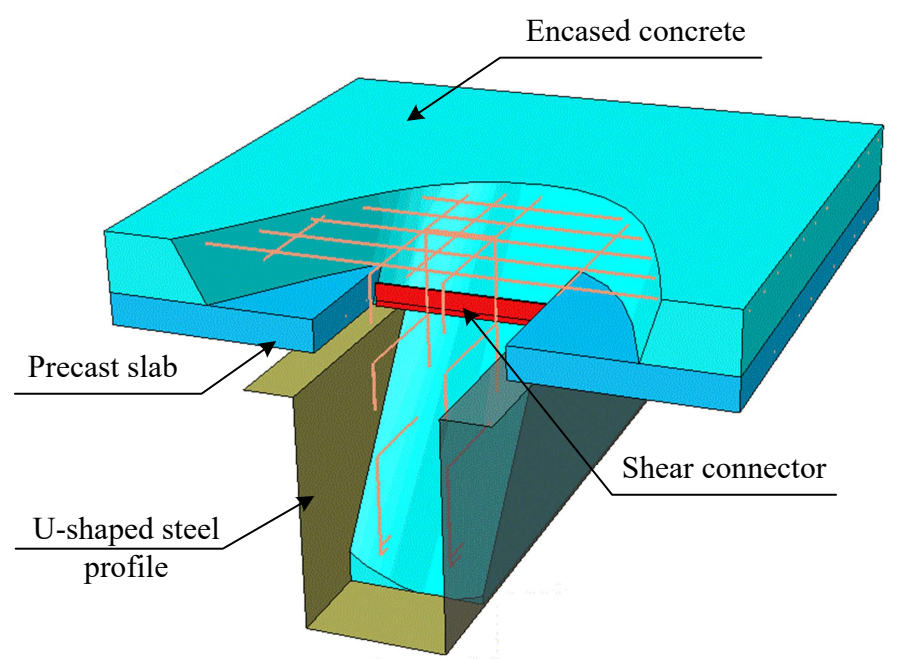

Figure 1: U-shaped steel-concrete hybrid beam (USCB).

\section{Experimental program}

An experimental program is developed to quantify the strength and deformation capacities of shear connectors as well as to gain an insight into the force transfer mechanism in the Ushaped steel-concrete hybrid beams. A modification of the typical push-out test setup proposed by Eurocode 4 [24], which is usually adopted for classic shear stud connectors, is made to represent the real situation of the U-shaped steel-concrete hybrid beams. Primarily, two experimental tests with two different types of connector cross-section are conducted in order to choose an appropriate connector type to be used in USCB; as stated earlier, the square and L-shaped connector crosssection are considered. Next, three additional tests are conducted for the selected appropriate connector type, L-shaped shear connector in this case. In the following, the detailed description of the experimental program is presented. 


\subsection{Geometric description of the test configuration}

The test setup consists of a universal testing machine with a capacity of $1500 \mathrm{kN}$, a U-shaped steel-concrete hybrid beam specimen, reaction blocks and bracing systems, see Fig. 2 and Fig. 3. The actuator is fixed to one end of the steel beam. It is attached to a $40 \mathrm{~mm}$-thick steel plate that serves as a platform for push-out test specimens. The $40 \mathrm{~mm}$ thick steel plate is welded to two $6 \mathrm{~mm}$-thick gussets, which are connected to the webs of steel beam at one end via twelve 20 mm-diameter high-strength bolts. At the other end of the specimen, the back side surface of the concrete floor is put in contact with a rigid steel beam. The specimen is positioned horizontally on 2 vertical supporting steel columns where at the top surface of their end-plate (with slotted holes), two greased PTFE plates are placed, allowing the horizontal displacement of the steel beam to occur. This test setup is similar to the one used by Lowe et al. [25] and Topkaya et al. [26]. The advantage of this setup is that there is only one slippage interface, compared to two interfaces for a typical push-out test.

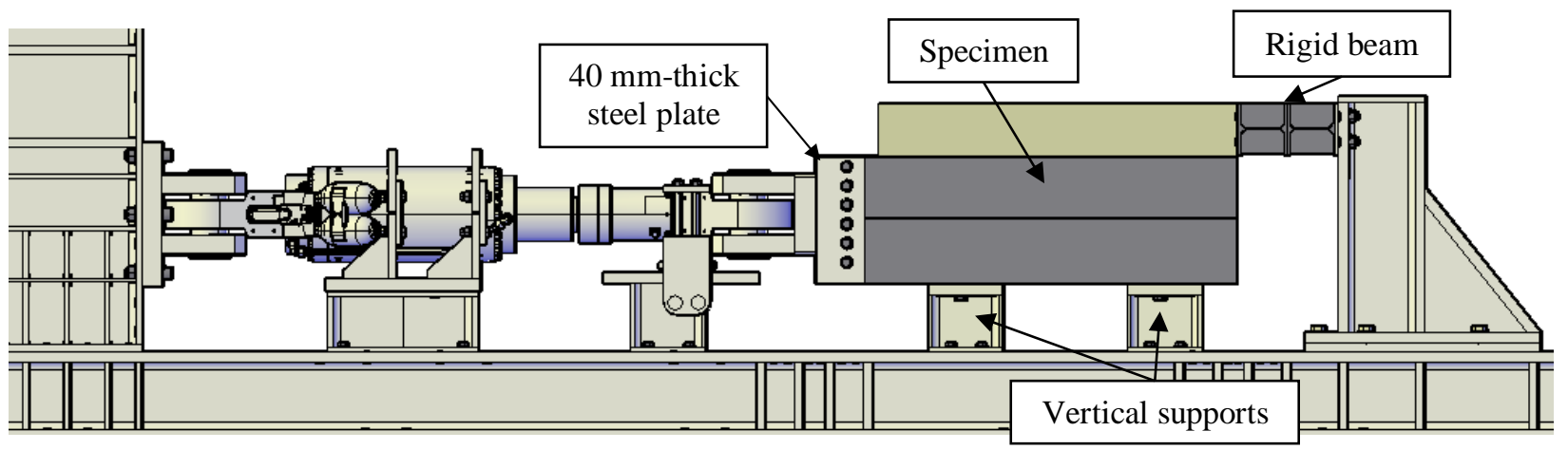

Figure 2: Schematic of push-out test setup.

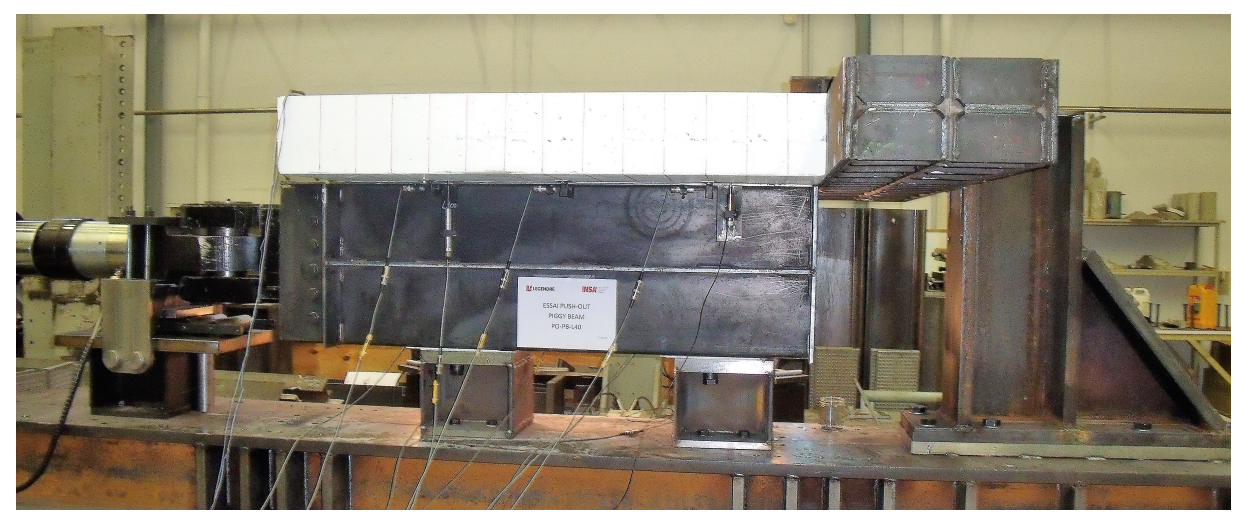

Figure 3: Side view of push-out test setup. 


\subsection{Test specimens}

The specimen consists of a U-shaped steel beam, two precast-slabs, a reinforced concrete beam encased in a U-shaped steel beam and several shear connectors. The internal surfaces of U-shaped steel beam are greased before concrete encasement to ensure that the force transfer between the two materials is done only through shear connectors. The geometry of the specimen is the following. U-shaped steel beam is $500 \mathrm{~mm}$ high, $300 \mathrm{~mm}$ wide and $6 \mathrm{~mm}$ thick. The webs are stiffened by horizontal and vertical plates in order to avoid a premature collapse of the specimens due to web buckling. The precast slabs are $70 \mathrm{~mm}$ thick and $450 \mathrm{~mm}$ wide. They are posed on each steel flange. The grid rebar ST35 is used for precast and slab reinforcement in which the rebar diameter is 7 $\mathrm{mm}$ and the spacing in transverse and longitudinal direction is $300 \mathrm{~mm}$ and $100 \mathrm{~mm}$, respectively. The detailed description of specimen cross-section and reinforcement is presented in Fig. 4c and Fig. 4d, respectively. The connectors are welded on the flanges of the steel beam. Five specimens with different types of connector are evaluated. The first specimen denoted "PO-S20", Fig. 4a, has 4 shear connectors with square-shaped section of $20 \times 20 \mathrm{~mm}$. The second specimen denoted "PO-L40", Fig. 4b, has 3 shear connectors with L-shaped section of $40 \times 40 \times 4 \mathrm{~mm}$. The third to fifth specimen denoted respectively "PO-L50a", "PO-L50b" and "PO-L50c" have 3 shear connectors with L-shaped section of $50 \times 50 \times 5 \mathrm{~mm}$. The spacing between each connector for all specimens is $300 \mathrm{~mm}$.

\subsection{Materials}

The concrete for RC beam-floor has a strength class of C25/30. The concrete characteristics at the day of test are determined on cylinder samples with dimensions of $11 \times 22 \mathrm{~cm}$. Due to the different usage of concrete in precast slab and $\mathrm{RC}$ beam-floor, the concrete characteristics of the precast slab are measured separately. Coupon samples are taken from the steel sheet, forming the U-section, and from the shear connector (L-angle and square section) used in the push-out specimens. Results of material characteristic tests are summarized in Table 1. It is worth mentioning that PO-L50a,b,c specimens are tested at an early age of the concrete in order to have a concrete strength at the day of test that is about $60 \%$ to $80 \%$ of concrete characteristic strength, as required by EC4 [24].

Table 1: Mean material properties.

\begin{tabular}{c|c|c|cc|cc}
\hline \multirow{2}{*}{ Specimen } & Concrete & Precast & \multicolumn{2}{|c|}{ Connectors } & \multicolumn{2}{c}{ U-shaped } \\
\cline { 2 - 5 } & $f_{c m}(\mathrm{MPa})$ & $f_{c m}(\mathrm{MPa})$ & $f_{y}(\mathrm{MPa})$ & $f_{u}(\mathrm{MPa})$ & $f_{y}(\mathrm{MPa})$ & $f_{u}(\mathrm{MPa})$ \\
\hline PO-S20 & 27.75 & 42.29 & 555 & 693 & & \\
\hline PO-L40 & 26.97 & 43.29 & 430 & 550 & & \\
\hline PO-L50a & 20.27 & 38.15 & & & & \\
PO-L50b & 21.29 & 38.79 & 325 & 445 & & \\
PO-L50c & 22.71 & 38.04 & & & & \\
\hline
\end{tabular}




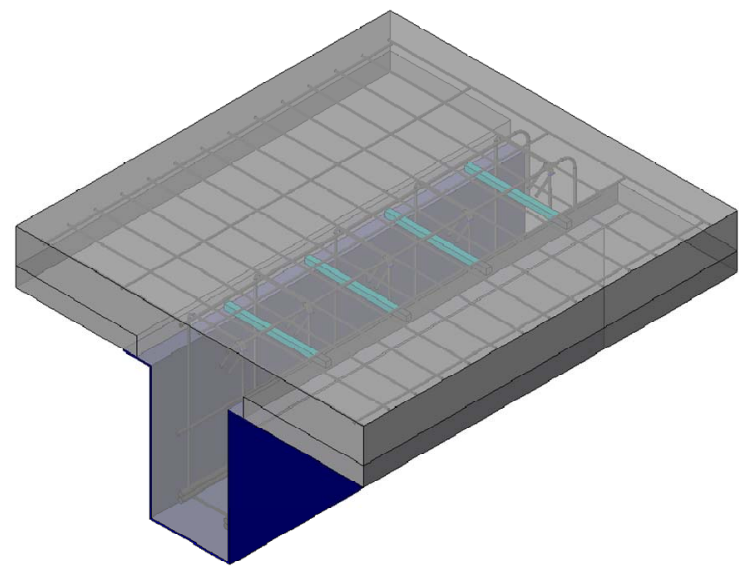

(a) Specimen with square bar connectors.

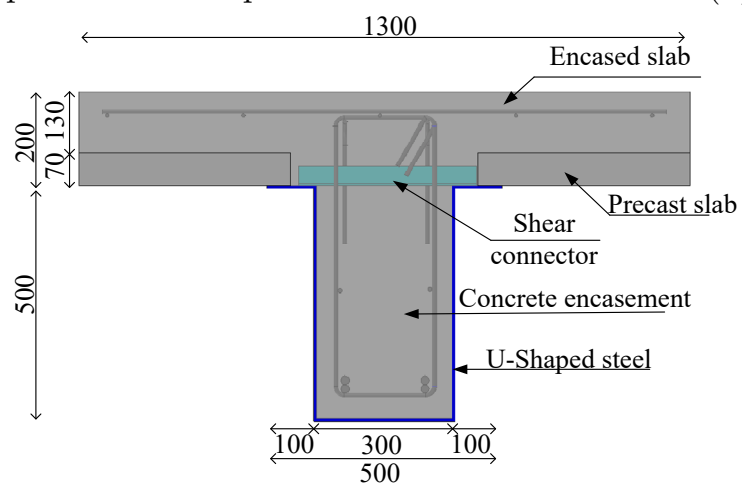

(c) Specimen cross-section detailing (dimension in $\mathrm{mm})$.

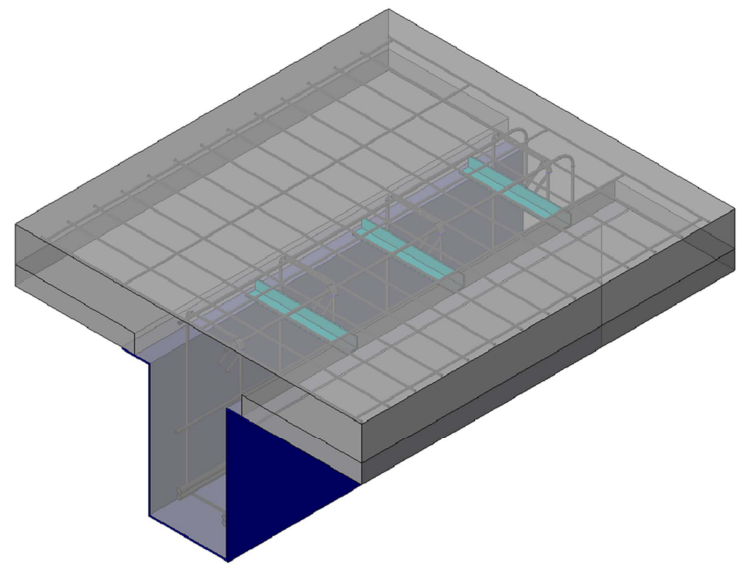

(b) Specimen with L-shaped connectors.

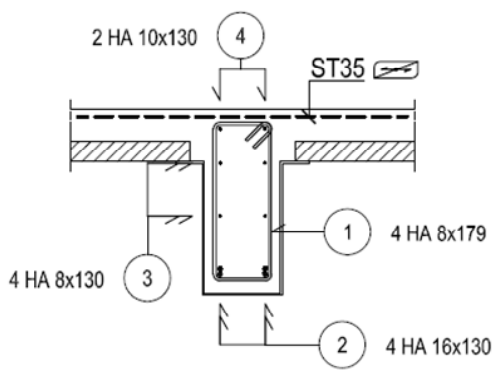

(d) Specimen rebar detailing.

Figure 4: Test specimen.

\subsection{Loading procedure and instrumentation}

The specimens are tested under monotonic loading. The compressive load is applied horizontally and monotonically on the specimen via a hydraulic jack. Monotonic loading involves a slow increment of the load using the displacement-control method with a rate of $0.015 \mathrm{~mm} / \mathrm{s}$. For PO-S20 and PO-L40 specimens, the loading is split into 3 stages. At first stage, the load is firstly increased monotonically up to $215 \mathrm{kN}$ (value estimated for service limit state design) before being decreased to zero. Thereafter, the loading is resumed at the second stage and increased up to $300 \mathrm{kN}$ (value estimated for ultimate limit state design) before being decreased once again to zero. At the final stage, the reloading is applied until the failure of the specimens. On the other hand, PO-L50(a,b,c) specimens are subjected to 25 loading-unloading cycles with a maximum load of $328 \mathrm{kN}$ (value estimated for service limit state design) and a minimum load of $50 \mathrm{kN}$ before being submitted to incremental loading up to failure. The force reading is recorded by the universal machine. To measure the relative horizontal displacement and vertical separation of the components, displacement sensors are installed. The measurement of the relative horizontal displacement (slip) between the 

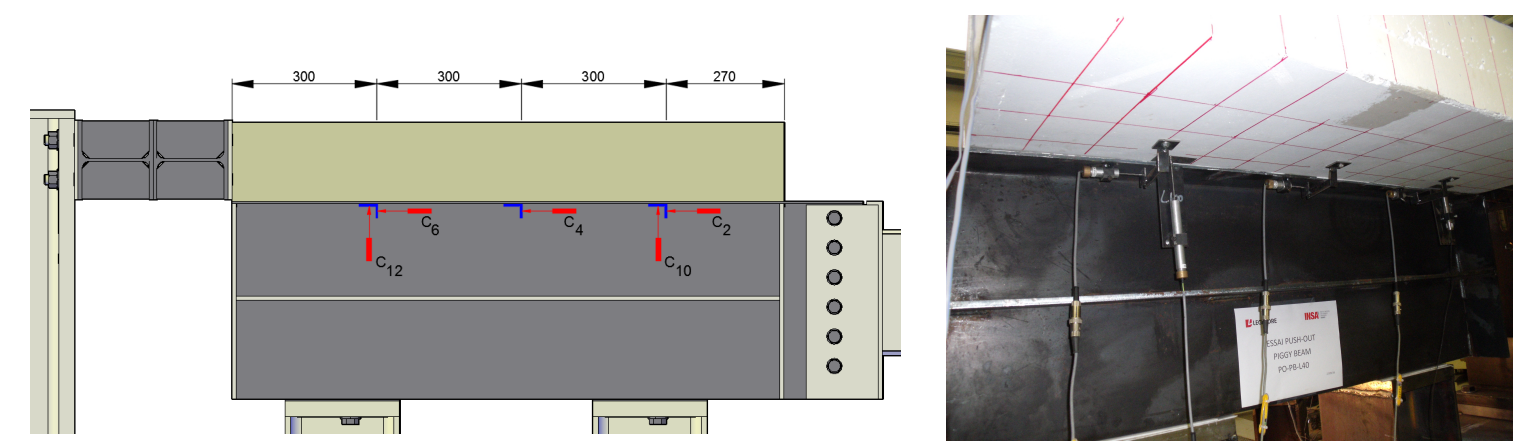

Figure 5: LVDT sensor installation.

concrete and the steel beam are made through six LVDT displacement sensors that are installed at both sides of the beam ( 3 at each side of the beam), at the location where the connectors are placed, see Fig. 5. Four LVDT displacement sensors (2 at each side) are installed to measure the vertical separation between the reinforced concrete and the steel beam (uplift). The displacement readings are recorded through a data acquisition system connected to the displacement transducers.

\subsection{Test results}

This section presents the experimental test results by highlighting the failure modes and the load-slip/uplift response of the specimens.

\subsubsection{Failure mode}

For PO-S20 and PO-L40 specimens, no concrete cracking is observed during the test. The failure mode of both specimens is associated with the failure of the connectors and/or the local concrete crushing. For PO-S20 specimen, the failure is due to the local concrete crushing. The failure mode observed in PO-L40 specimen is the connector fracture, see Fig. 6a, that is associated with the plastic deformation of connectors due to shear near the fillets between the angles of the cross-section and at the leg angle welded on the flange of the steel beam. This mode of failure leads to a large ductility in the force-slip response. The end of the plastic yielding is due to the fracture of the connector and of the welds. A failure mode similar to PO-L40 specimen is observed for POL50 $(\mathrm{a}, \mathrm{b}, \mathrm{c})$ specimens, see Fig. 6b. However, it is observed that at a load level near the ultimate load, concrete cracking appeared on top surface of concrete slab, on back surface in contact with rigid steel beam and on front surface at the junction between precast slab and concrete infill of POL50(a,b,c) specimens. Nevertheless, concrete cracking did not lead to total failure of the specimens. For PO-L50c specimen, the fracture of all connectors happened simultaneously. After removing the U-shaped steel beam from PO-L50c specimen, it appears that the concrete experienced inelastic deformations or local crushing/splitting, see Fig. 7. The gap, produced by local concrete crushing, allowed the connector to deform. Because of the deformation occurring in shear connector, the overall behavior of the L-shaped shear connector used in USCB is ductile. 


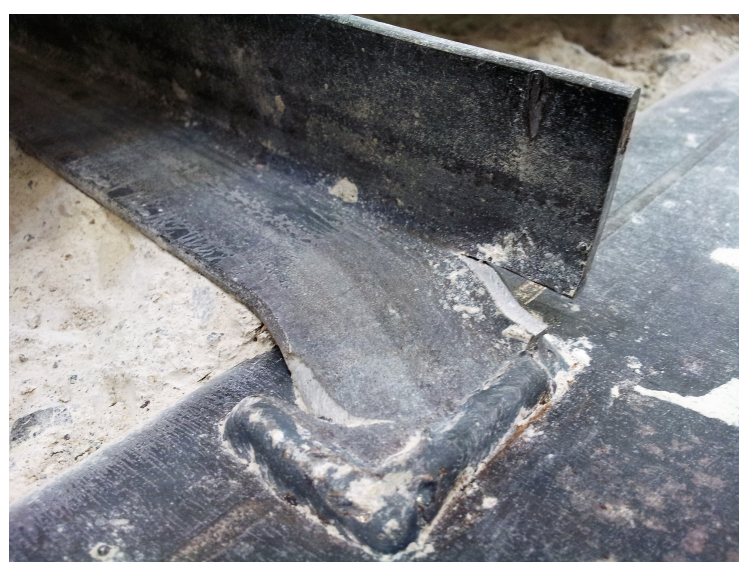

(a) $\mathrm{L} 40 \times 40 \times 4$.

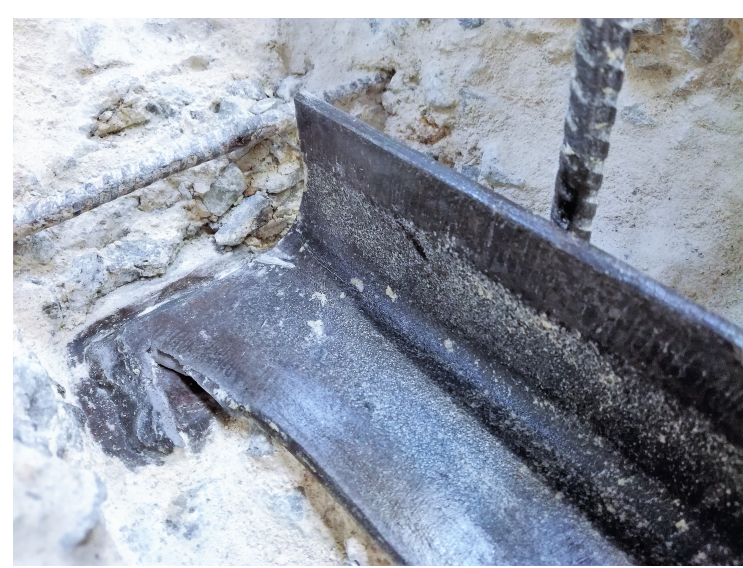

(b) $\mathrm{L} 50 \times 50 \times 5$.

Figure 6: Fracture of L-shaped shear connector.

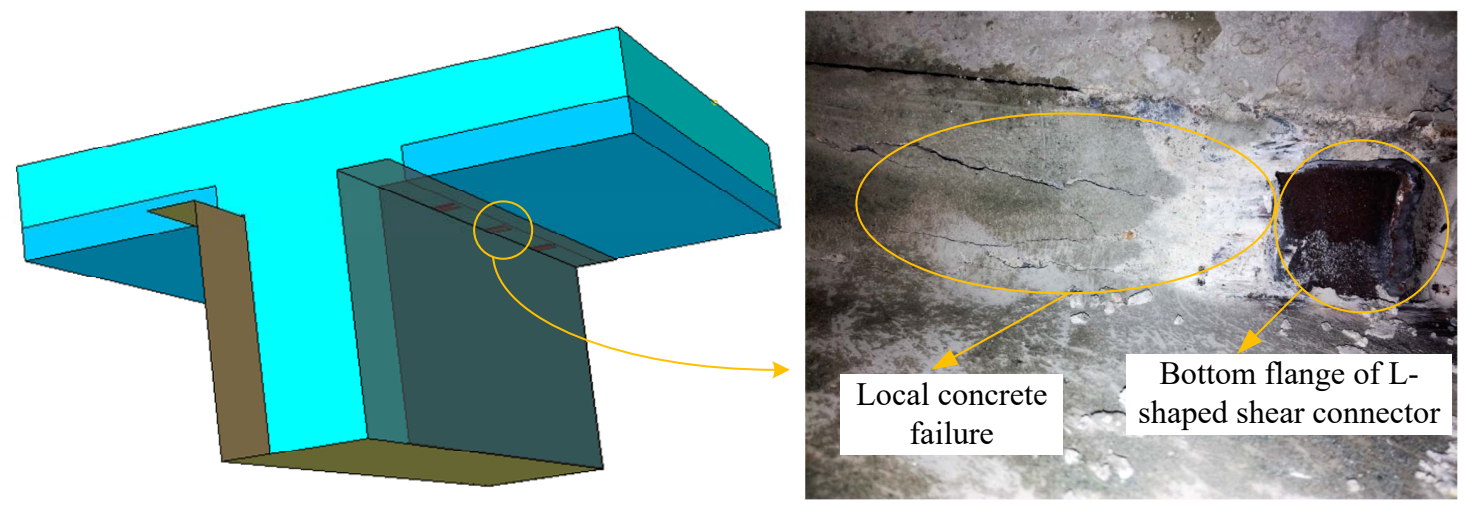

Figure 7: PO-L50c: concrete local crushing/splitting.

\subsubsection{Load-displacement response}

The relation between the push-out load and the mean slip as well as the mean uplift between the concrete beam-floor and the steel beam is illustrated in Fig. 8. The load-mean slip curve of PO-S20 specimen shows that after the ultimate load, the load capacity drops down rapidly. For specimens with L-shaped shear connectors, load reduction occurred in a slow rate after reaching the ultimate load. It proves that the specimens with L-shaped shear connectors present a ductile behavior while the one with square bar shear connectors, PO-S20, exhibits less ductility. Due to the lack of ductility, which is required in design codes for partial shear connection design, PO-S20 solution for USCB is withdrawn and no further discussed in this paper. The ultimate load and corresponding slip of each specimen are reported in Table 2 in which the ultimate slip determined by using EC4 criterion are also provided. Besides, it can be seen that at $80 \%$ of ultimate load after peak, the vertical separation between concrete and steel beam for each specimen is less than half of the longitudinal slip. It shows that according to EC4 [24], the shear connectors have a sufficient capacity in resisting the vertical separation between the concrete component and the steel beam. 

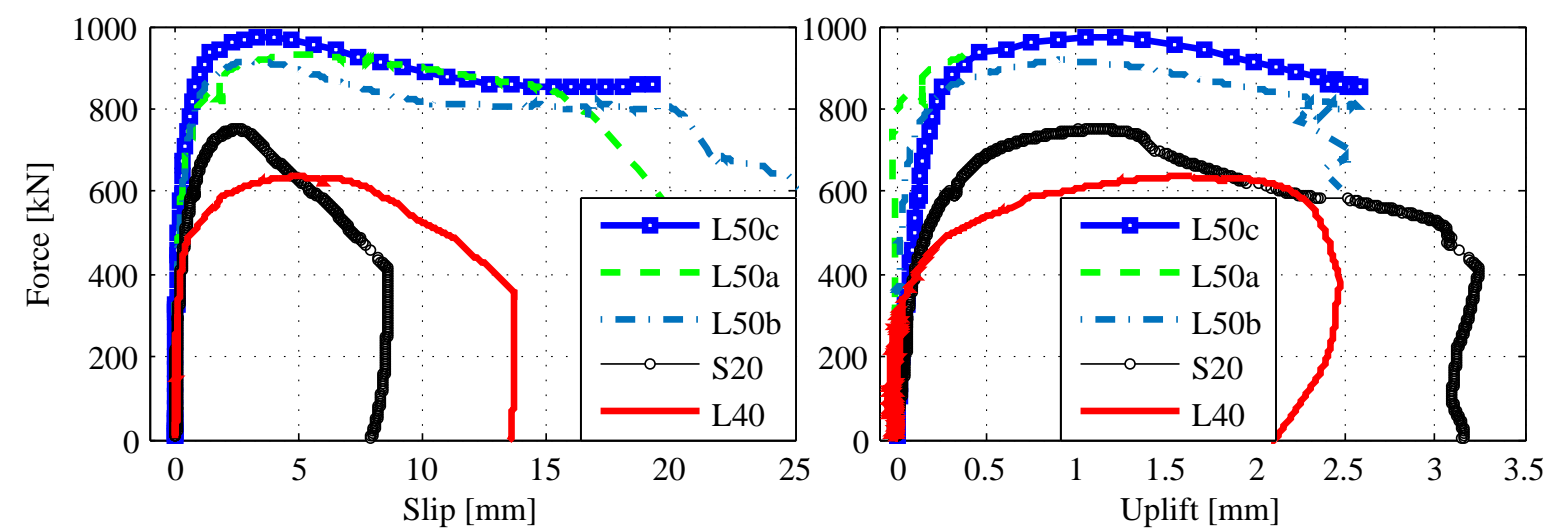

Figure 8: Load-mean slip/uplift response.

Table 2: Ultimate load and corresponding slip.

\begin{tabular}{cccccc}
\hline Specimen & PO-S20 & PO-L40 & PO-L50a & PO-L50b & PO-L50c \\
\hline$P_{\max }(\mathrm{kN})$ & 748.6 & 637.1 & 932.1 & 916.5 & 975.9 \\
$\delta_{\max }(\mathrm{mm})$ & 2.743 & 5.054 & 5.081 & 3.032 & 3.341 \\
$\delta_{u, E C 4}(\mathrm{~mm})$ & 4.09 & 8.90 & 15.49 & 9.59 & 11.04 \\
\hline
\end{tabular}

\section{Finite element simulations}

In order to get further information, a numerical simulation is performed on ABAQUS-Explicit. Since the use of square bar shear connectors is not a solution for partial shear connection design in U-shaped steel-concrete hybrid beam, FEA is performed only for specimens with L-shaped shear connectors. All main components that may affect the behavior of shear connection are considered in the model. By taking advantage of the symmetry, only a half of the specimen is simulated.

\subsection{Finite element type and mesh}

The components are modeled in separate parts as presented in Fig. 9. The concrete component is meshed with combined solid elements C3D8R and C3D6R available in ABAQUS library. The former element type is an 8-node brick element and the latter is a 6-node linear triangular prism element. Each node has three translational degrees of freedom. C3D8R element is also used for meshing shear connectors and welds. The steel beam is meshed with 4-node shell (S4R) element while the reinforcement bars are meshed with beam elements (B31). The overall mesh size of the concrete component, steel beam, shear connectors, welds and of the rebars are $20 \mathrm{~mm}, 20 \mathrm{~mm}, 1$ $\mathrm{mm}, 2 \mathrm{~mm}$ and $20 \mathrm{~mm}$, respectively. For concrete and steel beam components, a refined mesh is used at zones in contact with shear connectors.

\subsection{Constraints and contact interactions}

Once all parts of the model are positioned together into an assembly, appropriate constraints are used to describe the interaction between components. The surfaces in contact between shear 


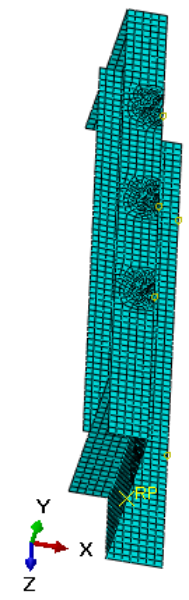

a) Steel beam (S4R)

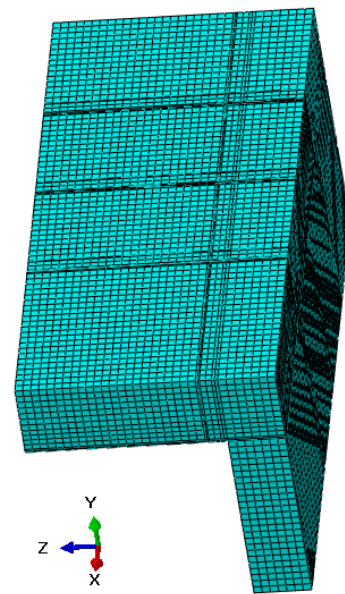

b) Concrete beam-floor (C3D8R \& C3D6R)

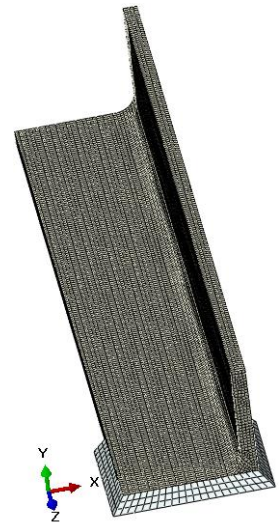

c)

Figure 9: Finite element model.

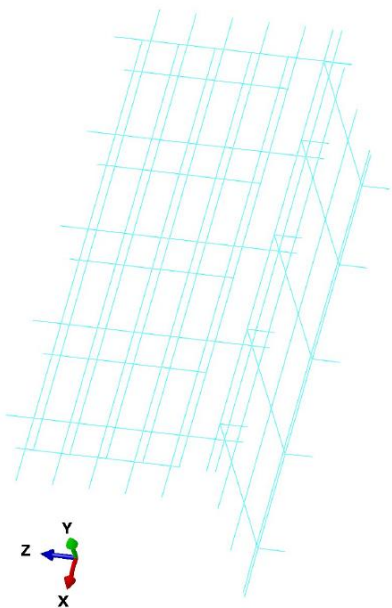

d) Rebars

(B31)

connectors and welds are tied together. The bottom surfaces of the latter are tied to the surface of the beam flange. This is equivalent to the actual push-out specimen where shear connectors remain tied to the steel beam flange via welding. For rebars which are placed inside the concrete beam-floor, the embedded constraint is applied. In this constraint, the translational DOF of the nodes on the rebar elements are constrained to the interpolated values of the corresponding DOF of the concrete element. The slip and debond of the rebar is ignored. Contact interactions are applied for the remaining contact surfaces. The interaction properties of the contact interactions used in the model are defined by the tangential and normal behavior to the surfaces. Since the interior surfaces of the U-shaped steel beam are greased, the frictionless for tangential behavior is used at the contact surfaces between steel beam and other components. The penalty friction formulation is used for tangential behavior of the remaining contact surfaces with a coefficient of friction equal to 0.3. The default normal behavior (hard contact) is assumed for all contact surfaces. This normal behavior allows a minimum penetration of the slave surface into the master surface. For all contact pairs, the penalty contact formulation is used.

\subsection{Loading and boundary conditions}

Since ABAQUS/Explicit is a dynamic analysis program, a static solution is required for pushout test simulation. To obtain a quasi-static solution from the explicit dynamic analysis, the kinetic energy is suggested to be controlled within $5 \%-10 \%$ of the internal energy [27]. This criterion can be reached by a slow loading rate. Different loading rates with displacement controlled are attempted in the simulation and the optimum rate is found to be $0.33 \mathrm{~mm} / \mathrm{s}$. Moreover, the displacement loading is slowly applied by means of a smooth amplitude function to reduce the dynamic effect of the inertial forces at the beginning and at the end of loading. Besides, the semi-automatic mass scaling method in ABAQUS/Explicit is adopted to achieve a balance between solution time and 


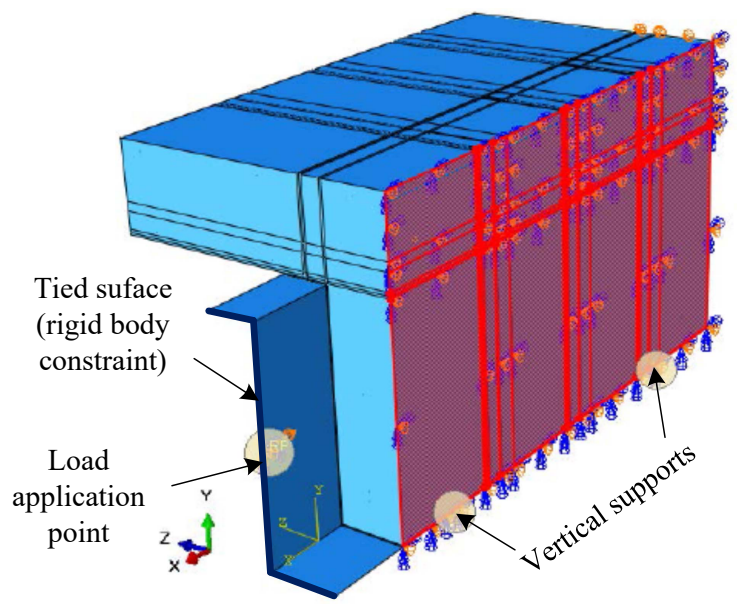

(a) Symmetric plane, vertical supports and load application point.

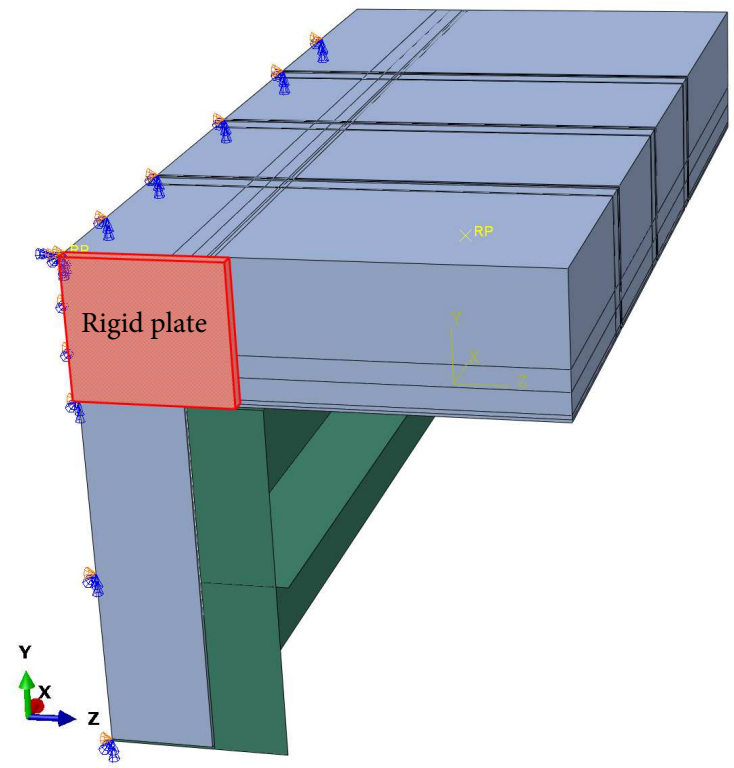

(b) Support representing contact surface with the rigid beam.

Figure 10: Boundary conditions.

accuracy.

The boundary condition applied to the median plane of the model (symmetric in Z-axis) is based on the symmetry, as shown in Fig. 10a. The translational displacement in Y-direction is restrained at nodes on the bottom flange of steel beam (the position of vertical supports). The loading is applied by introducing an axial displacement in X-direction at steel cross-section that is tied using rigid body constraint. The reference point of the latter is fixed in all remaining degrees of freedom. At the other end of the specimen, the rigid plate representing the contact surface between concrete floor and rigid steel beam defined in Fig. 10b (surface observed during the experimental tests) is fixed in all directions at its reference point.

\subsection{Concrete material model}

The concrete constitutive model used in [28] is adopted. The nonlinear behavior of the concrete material in compression and tension is presented by a uniaxial compressive stress-strain curve and a tensile stress-crack width relationship, see Fig. 11a and Fig. 11b, respectively. The compressive stress-stain curve is split into three parts. The first part is assumed to be elastic when the stress is lesser than $0.4 f_{c}$, where $f_{c}$ is the compressive cylinder strength of concrete. The elastic modulus is determined by:

$$
E_{c}=22000\left(f_{c}\right)^{1 / 3}
$$




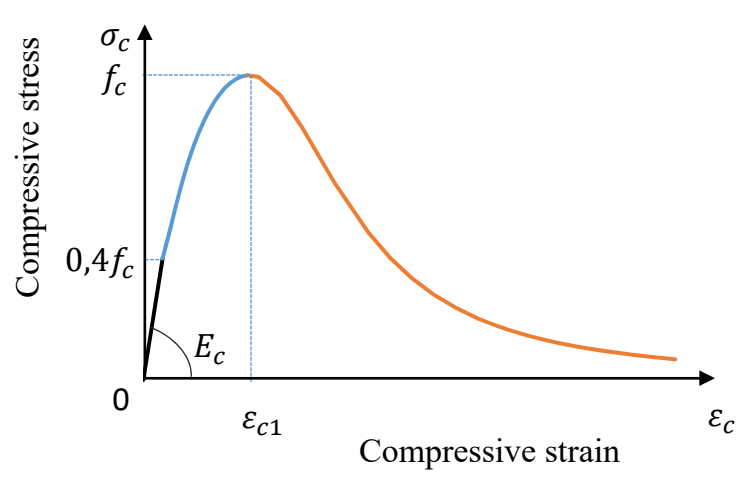

(a) Compression.

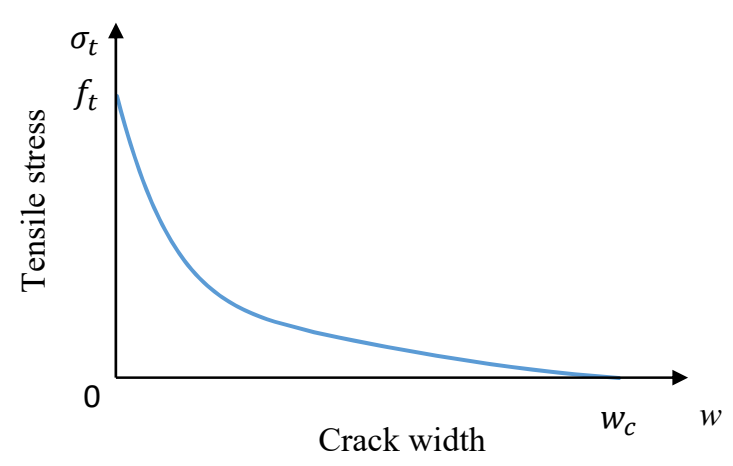

(b) Tension.

Figure 11: Concrete constitutive model.

The second part is a nonlinear parabolic portion ranging from the proportion limit stress $0.4 f_{c}$ to the peak stress $f_{c}$, described by the following expression [29]:

$$
\sigma_{c}=\frac{k \eta-\eta^{2}}{1+(k-2) \eta} f_{c}
$$

where $\sigma_{c}$ is the concrete compressive stress (MPa); $k$ is a constant expressed by $k=1.05 E_{c} \varepsilon_{c 1} / f_{c}$ in which $\varepsilon_{c 1}=0.7 f_{c}^{0.31} / 1000$; and $\eta$ is the ratio of stain to peak strain, $\eta=\varepsilon_{c} / \varepsilon_{c 1}$. The third part of the curve which corresponds to the descending segment is given by [30]:

$$
\sigma_{c}=\left(\frac{2+\gamma_{c} f_{c} \varepsilon_{c 1}}{2 f_{c}}-\gamma_{c} \varepsilon_{c}+\frac{\varepsilon_{c} \gamma_{c}}{2 \varepsilon_{c 1}}\right)^{-1}
$$

where $\gamma_{c}=\frac{\pi^{2} f_{c} \varepsilon_{c 1}}{2\left[\frac{G_{c h}}{l_{e q}}-0.5 f_{c}\left(\varepsilon_{c 1}(1-b)+b \frac{f_{c}}{E_{c}}\right)\right]^{2}}$ in which $b$ is the ratio of compressive plastic strain to crushing strain, $b=\varepsilon_{c}^{p l} / \varepsilon_{c}^{c h} ; G_{c h}$ is the crushing energy per unit area; and $l_{e q}$ is the characteristic length. The latter depends on the mesh size, the type of finite element and the crack direction [30, 31]. For the validation of the FE model, the characteristic length is taken equal to $220 \mathrm{~mm}$ which is the height of concrete cylinder specimen.

For un-cracked concrete subjected to tension, a linear stress-strain relationship up to the tensile strength, $f_{t}$, is adopted. Moreover, the modulus of elasticity in tension is assumed to equal to the one in compression. The following nonlinear stress-crack width relationship is adopted for cracked concrete [32]:

$$
\frac{\sigma_{t}}{f_{t}}=\left[1+\left(c_{1} \frac{w}{w_{c}}\right)^{3}\right] \exp \left(-c_{2} \frac{w}{w_{c}}\right)-\frac{w}{w_{c}}\left(1+c_{1}^{3}\right) \exp \left(-c_{2}\right)
$$

where $f_{t}$ is the tensile strength determined by $f_{t}=0.3\left(f_{c}-8\right)^{2 / 3}(\mathrm{MPa}) ; w$ is the crack width $(\mathrm{mm}) ; w_{c}$ is the critical crack opening $(\mathrm{mm})$ given by $w_{c}=5.14 G_{F} / f_{t}$ in which the fracture energy $G_{F}(\mathrm{~N} / \mathrm{mm})$ per unit area can be calculated as $G_{F}=0.073 f_{c}^{0.18}$; and the constants $c_{1}$ and $c_{2}$ are 
equal to 3 and 6.93, respectively. The tensile stress in concrete can be expressed in terms of tensile strain using the strain-crack opening relationship as follow [28]:

$$
\varepsilon_{t}=f_{t} / E_{c}+w / l_{e q}
$$

In push-out test simulations, the Concrete Damaged Plasticity model available in ABAQUS material library is adopted. In this model, yielding parts of the concrete in tension and compression are treated separately. The parameters used to define the concrete damaged plasticity are the following. The material dilation angle $(\psi)$, eccentricity $(\epsilon)$ are taken as $15^{\circ}$ and 0.1 , respectively. The ratio of biaxial compressive strength to uniaxial compressive strength $\left(\sigma_{b 0} / \sigma_{c 0}\right)$ is taken as 1.16 .

\subsection{Steel material models}

The stress-strain relationship of shear connectors is represented by a tri-linear curve, see Fig. 12. The initial regime is assumed to be elastic followed by a stage of yielding and finally a branch of strain hardening. The stress-strain behaviors in tension and compression are assumed to be the same. The nominal or engineering ultimate strain, $\varepsilon_{u}^{n o m}$, was set to be $20 \%$. It is worth mentioning that when defining plasticity data in ABAQUS, true stress and true strain must be used for a simulation with large strains. The relationship between true strain and nominal strain is established by

$$
\varepsilon^{\text {true }}=\ln \left(1+\varepsilon^{\text {nom }}\right)
$$

The relationship between true stress and nominal stress and strain is

$$
\sigma^{\text {true }}=\sigma^{\text {nom }}\left(1+\varepsilon^{\text {nom }}\right)
$$

Table 3 shows the true stress-strain data for the L-shaped shear connectors as input in ABAQUS.

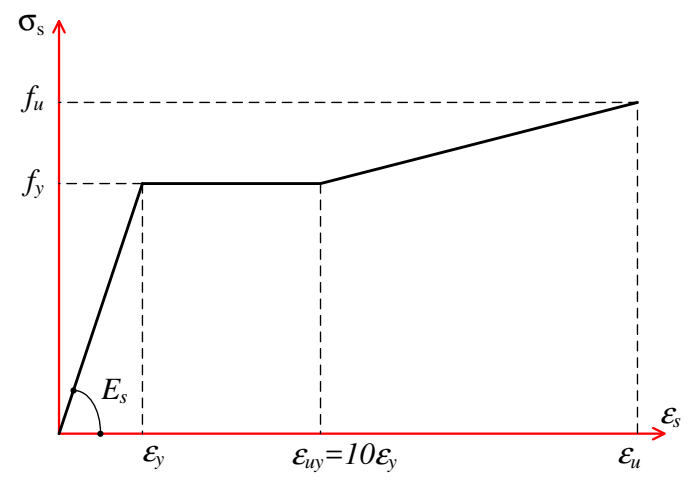

Figure 12: Engineering stress-strain relationship model for shear connectors.

Besides, an elastic-perfectly plastic model is adopted for U-shaped steel beam and reinforcing bars. The modulus of elasticity and the Poisson's ratio of all steel materials used in the model are 210 GPa and 0.3, respectively. 
Table 3: Steel connector properties.

\begin{tabular}{|c|c|c|c|}
\hline \multicolumn{2}{|c|}{$\mathrm{L} 40 \times 40 \times 4$} & \multicolumn{2}{|c|}{$\mathrm{L} 50 \times 50 \times 5$} \\
\hline Yield stress $(\mathrm{MPa})$ & Plastic strain & Yield stress (MPa) & Plastic strain \\
\hline 430.88 & 0.0000 & 325.50 & 0.0000 \\
\hline 438.80 & 0.0182 & 330.03 & 0.0138 \\
\hline 660.00 & 0.1792 & 534.00 & 0.1798 \\
\hline
\end{tabular}

\subsection{Validation of finite element model}

In order to verify the developed finite element model, the push-out tests presented previously are modeled using the assumptions described above. The shear connection capacity obtained from the tests $\left(P_{\text {Test }}\right)$ and finite element analysis $\left(P_{F E}\right)$ as well as the load-slip and load-uplift response of the test specimens, including its failure modes, are investigated. Table 4 shows a comparison of the capacities of shear connection obtained experimentally and numerically. It can be seen that a good agreement between both results has been achieved. The experimental load-slip and load-uplift curve is compared with the numerical curve obtained from the finite element analysis, see Fig. 13 and Fig. 14. Generally, a good agreement between the pairs has been attained. It is shown that the finite element models successfully predicted the shear connection capacity and the stiffness of the L-shaped shear connectors used for USCB.

Table 4: Comparison of ultimate loads obtained from FEA against experimental results.

\begin{tabular}{ccccc}
\hline Specimen & PO-L40 & PO-L50a & PO-L50b & PO-L50c \\
\hline$P_{\text {Test }}(\mathrm{kN})$ & 637.1 & 932.1 & 916.5 & 975.9 \\
$P_{F E}(\mathrm{kN})$ & 634.67 & 999.14 & 999.14 & 999.14 \\
$P_{F E} / P_{\text {Test }}$ & 1.00 & 1.07 & 1.09 & 1.02 \\
\hline
\end{tabular}
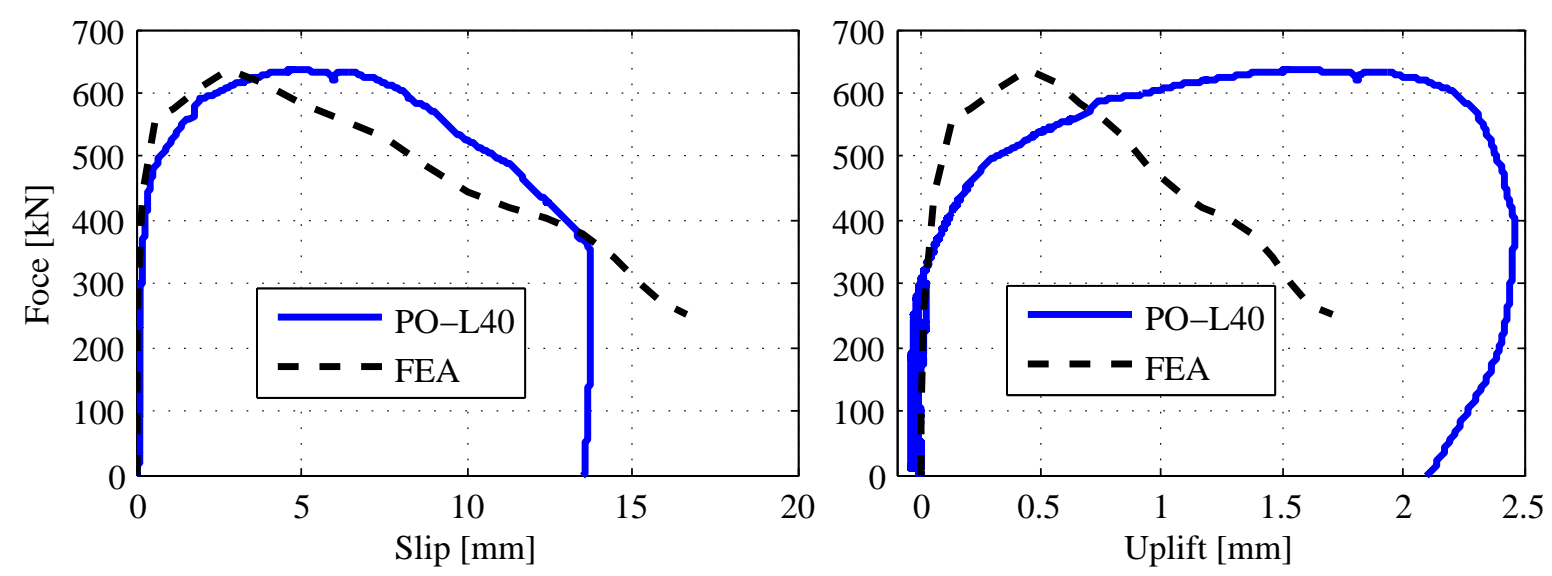

Figure 13: Comparison of FEA against experimental results of PO-L40 specimen. 

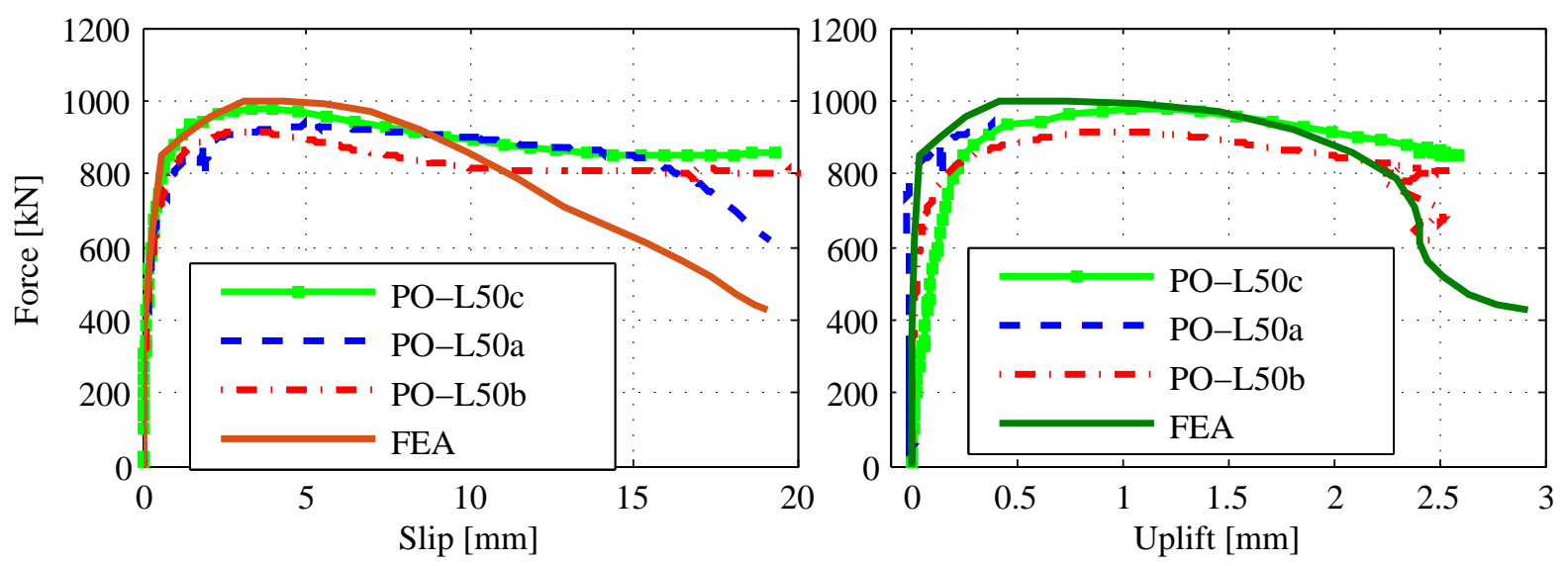

Figure 14: Comparison of FEA against experimental results of PO-L50a,b,c specimen.

Fig. 15 and Fig. 16 show the stress contour and the deformed shape of the shear connector at different load levels up to failure for PO-L40 and PO-L50a,b,c specimen, respectively. From the stress contours, it is shown that the local failure of concrete in compression occurs in front of both bottom leg angle and the fillet between the angles of the L-shaped shear connector. Moreover, the double shearing of the L-shaped shear connector is observed.

\subsection{Parametric study}

The following parametric study is performed by evaluating key parameters, for instance the concrete strength $\left(f_{c}\right)$, the cross-section of L-angle, the length of the shear connector welded to the steel beam flange $\left(L_{w}\right)$, as well as the different thicknesses of concrete slab $\left(H_{c}\right)$. The global geometry of PO-L40 specimen is adopted. Three cross-sections of shear connectors are evaluated: $\mathrm{L} 30 \times 30 \times 3, \mathrm{~L} 40 \times 40 \times 4$ and $\mathrm{L} 50 \times 50 \times 5$. The parametric study is summarized in Table 5 . At least three different values are considered for each evaluated variable.

The effect of concrete compressive strength is shown in Fig. 17. It is clear that the shear bearing capacity of the connector increases with increasing concrete strength. Fig. 18 shows the effects of the other evaluated parameters on shear capacity of the L-shaped shear connectors. The vertical axis in Fig. 16 represents the ratio of the ultimate load for each case-study to the mean value of those corresponding to the three cases for an evaluated variable. As expected, the cross-section of the L-shaped shear connector influence significantly the shear capacity of the connector. In fact, a larger L-angle cross-section has a larger flange thickness and a larger size of fillet that provide a higher shear resistance. It can be also seen that the shear capacity of the shear connector is directly related to the length of weld, $L_{w}$; a longer length of the weld provides a larger shear capacity of the connector. Furthermore, a larger thickness of concrete slab provides a larger bearing strength. All the forces presented on vertical axis in Fig. 17 and Fig. 18 correspond to the total applied load 

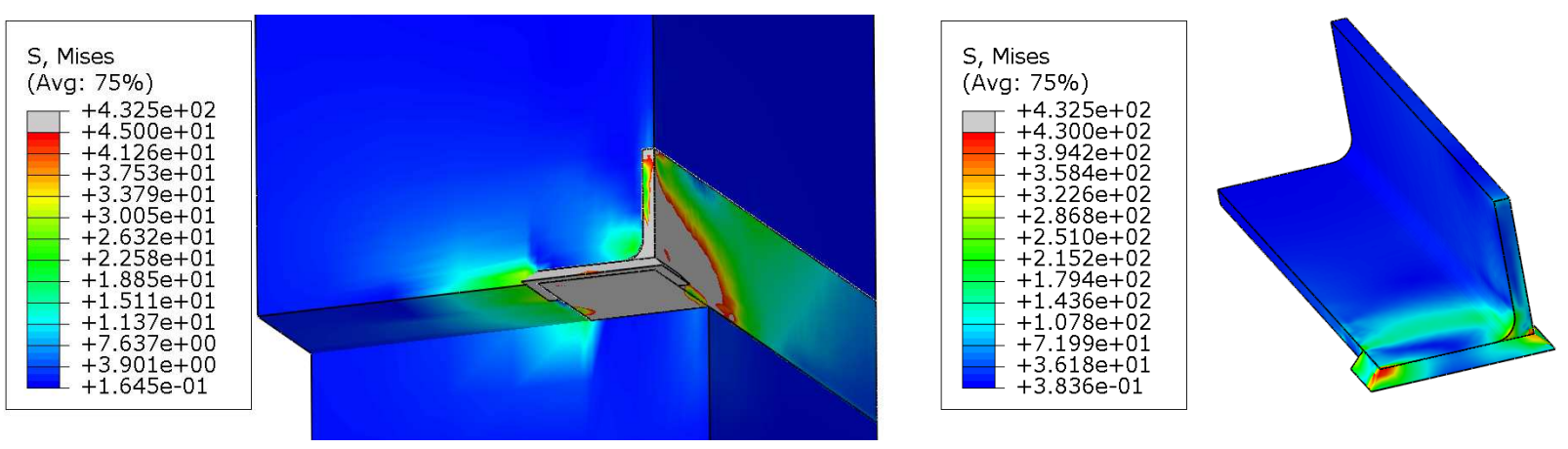

(a) Load level $254 \mathrm{kN}$
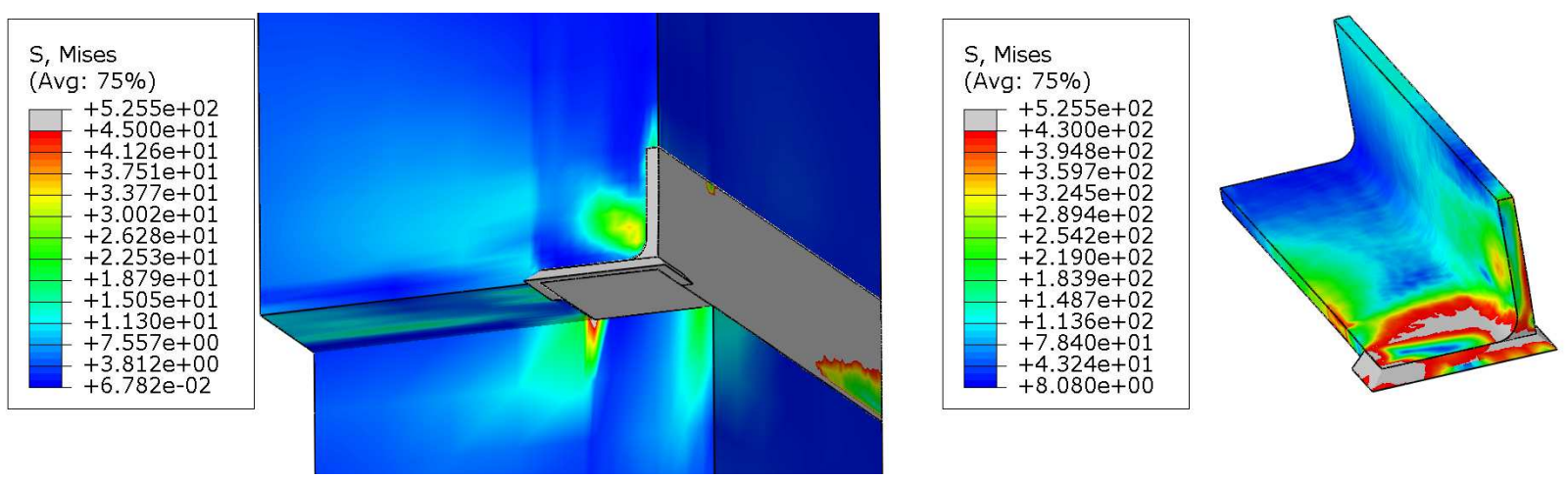

(b) Load level $560 \mathrm{kN}$
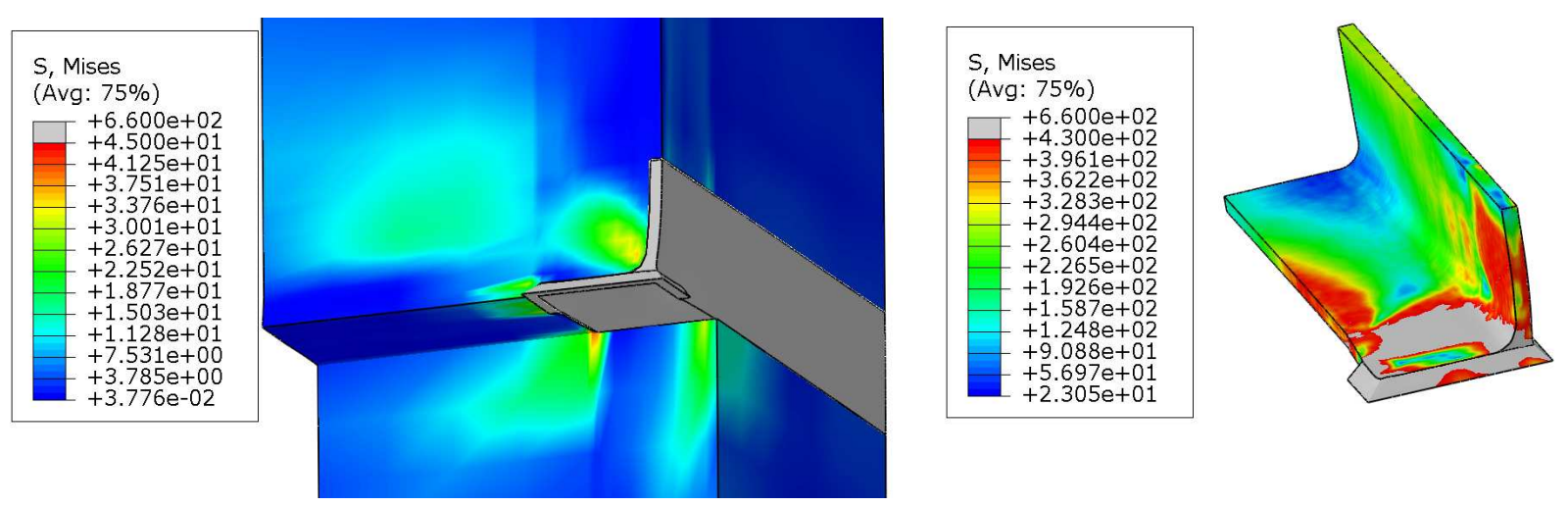

(c) Load level $634 \mathrm{kN}$

Figure 15: Stress contours and deformed shapes of FE model for PO-L40 specimen at various load levels.

in FE simulation.

\section{Proposal of a new equation predicting the shear capacity of shear connector}

To the best of our knowledge, there is currently no available formulation for determining the shear bearing capacity of the L-shaped shear connector used in USCB. To fill in this gap, a new 

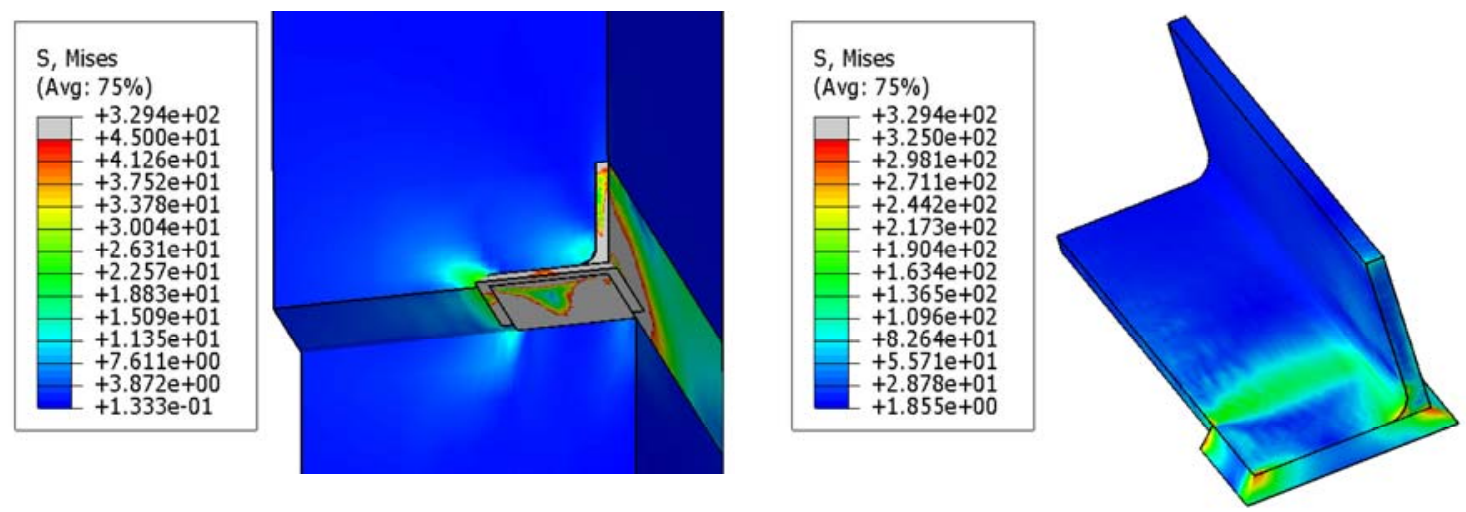

(a) Load level $347 \mathrm{kN}$
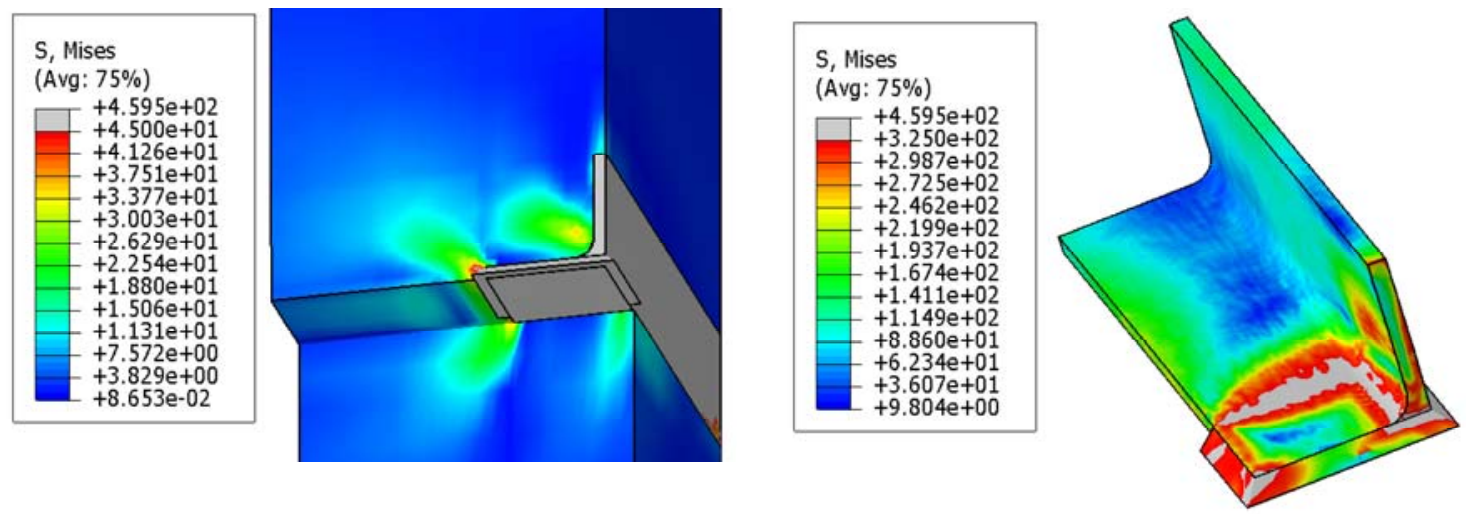

(b) Load level $855 \mathrm{kN}$
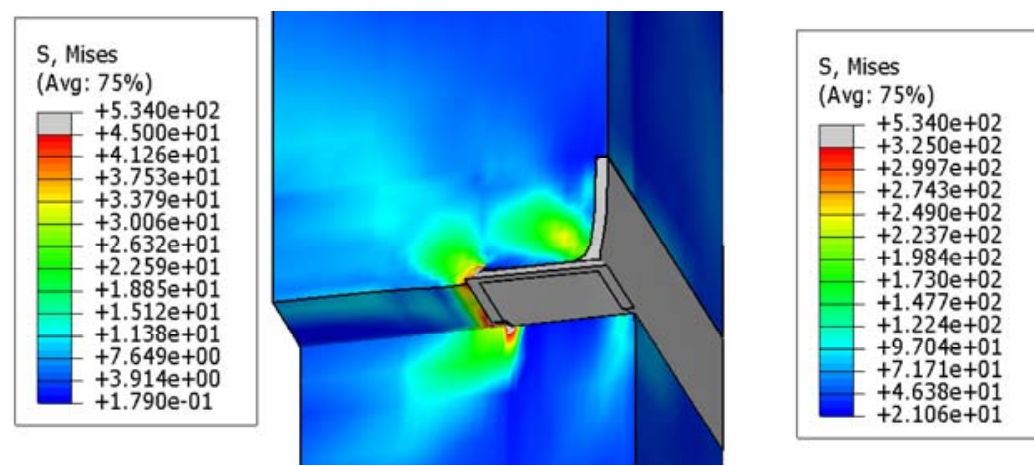

(c) Load level $999 \mathrm{kN}$

Figure 16: Stress contours and deformed shapes of FE model for PO-L50 specimen at various load levels.

equation is developed and proposed in this paper. The proposed equation is derived based on the observation of the deformation of shear connectors and of the stress pattern obtained from FEA. The results of the parametric study described earlier enhance the derivation of the formulation by 
Table 5: Summary of case-studies.

\begin{tabular}{|c|c|c|c|c|c|}
\hline \multicolumn{3}{|c|}{ L-angle } & \multicolumn{2}{|c|}{ Concrete } & \multirow{2}{*}{$\frac{\text { Length of welds }}{L_{w}(\mathrm{~mm})}$} \\
\hline Cross-section & $f_{y}(\mathrm{MPa})$ & $f_{u}(\mathrm{MPa})$ & $f_{c}(\mathrm{MPa})$ & $h_{c}(\mathrm{~mm})$ & \\
\hline \multirow{5}{*}{$\mathrm{L} 30 \times 30 \times 3$} & 235 & 360 & 35 & 200 & 40 \\
\hline & 335 & 455 & 35 & 200 & 40 \\
\hline & 355 & 510 & 35 & 200 & 40 \\
\hline & 430 & 550 & 35 & 200 & 40 \\
\hline & 235 & 360 & 42 & 200 & 30 \\
\hline \multirow{6}{*}{$\mathrm{L} 40 \times 40 \times 4$} & 430 & 550 & 27 & 200 & 20 \\
\hline & 430 & 550 & 27 & 200 & 30 \\
\hline & 430 & 550 & 27 & 200 & 40 \\
\hline & 235 & 360 & 42 & 200 & 30 \\
\hline & 430 & 550 & 35 & 200 & 30 \\
\hline & 430 & 550 & 42 & 200 & 30 \\
\hline \multirow{17}{*}{$\mathrm{L} 50 \times 50 \times 5$} & 235 & 360 & 42 & 200 & 30 \\
\hline & 235 & 360 & 35 & 200 & 30 \\
\hline & 235 & 360 & 27 & 200 & 30 \\
\hline & 355 & 510 & 27 & 200 & 20 \\
\hline & 355 & 510 & 35 & 200 & 20 \\
\hline & 355 & 510 & 42 & 200 & 20 \\
\hline & 325 & 445 & 10 & 200 & 40 \\
\hline & 325 & 445 & 27 & 200 & 40 \\
\hline & 325 & 445 & 35 & 200 & 40 \\
\hline & 325 & 445 & 42 & 200 & 40 \\
\hline & 325 & 445 & 60 & 200 & 40 \\
\hline & 325 & 445 & 27 & 150 & 40 \\
\hline & 325 & 445 & 35 & 150 & 40 \\
\hline & 325 & 445 & 42 & 150 & 40 \\
\hline & 325 & 445 & 27 & 120 & 40 \\
\hline & 325 & 445 & 35 & 120 & 40 \\
\hline & 325 & 445 & 42 & 120 & 40 \\
\hline
\end{tabular}

means of a set of data for a regression analysis.

The experimental tests show that the failure of tested specimens is associated with the local concrete crushing and with the plastic deformation of connectors due to shear near the fillets between the angles of the cross-section and at the leg angle welded on the flange of the steel beam. As a consequence, the shear connector resistance may be provided by two parts: shear resistance of the connector and concrete contribution. The former is characterized by two shear plans while the latter is assumed to be idealized by a rectangular stress block. The latter assumption for concrete 


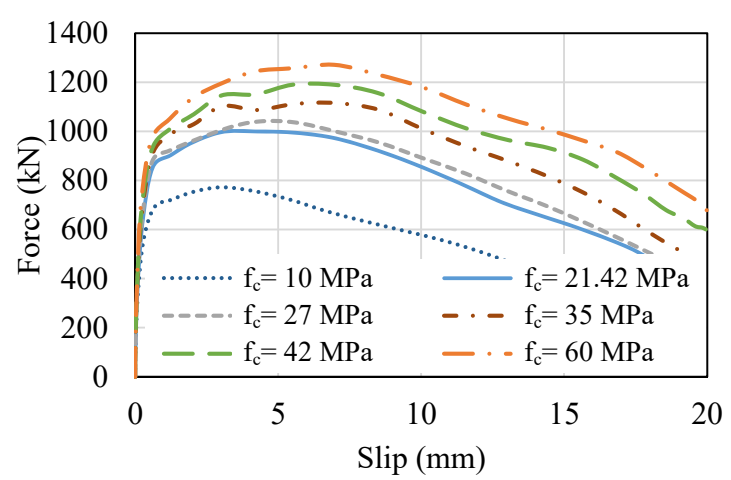

(a) Load-slip behavior.

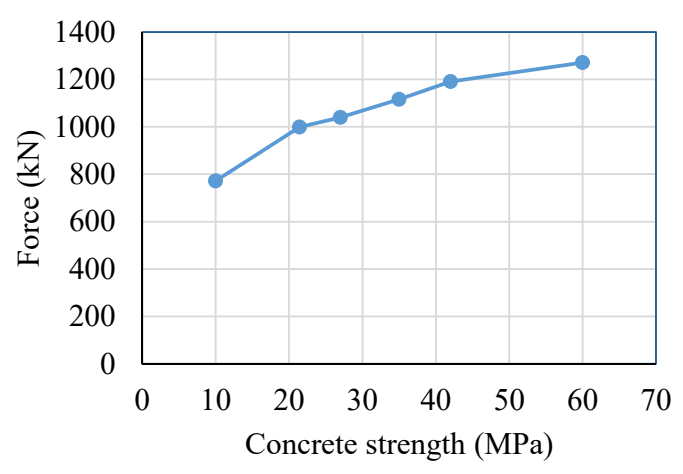

(b) Shear capacity.

Figure 17: Concrete strength effect on shear bearing capacity of 3 L50-shear connectors.

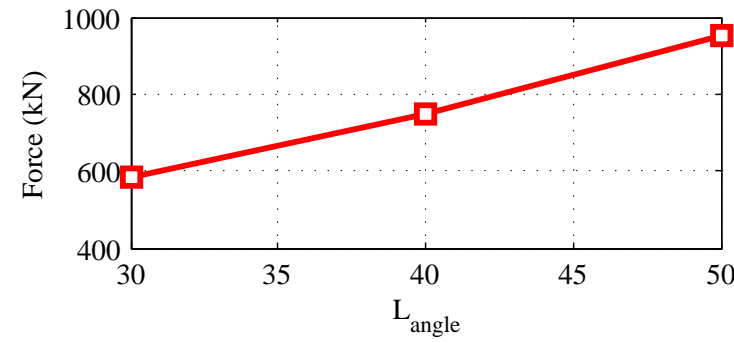

(a) L-shaped section.

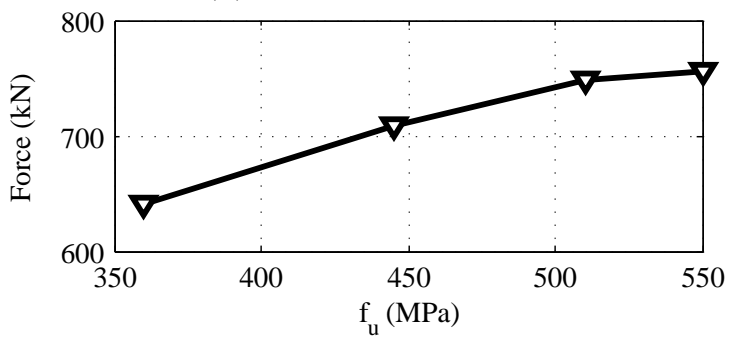

(c) Connector ultimate strength.

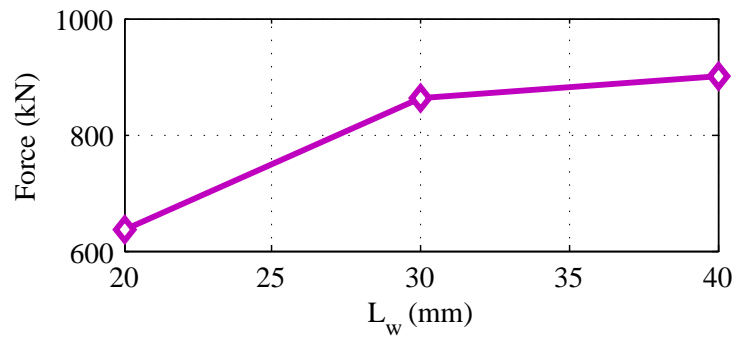

(b) Welded length.

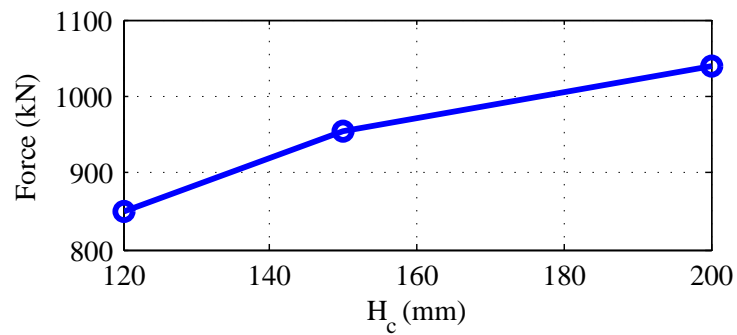

(d) Concrete deck thickness.

Figure 18: Effects of evaluated parameters on shear capacity of the L-shaped shear connectors.

pressure around shear connectors is made in order to calibrate the formulation. The equation predicting the shear bearing capacity of one shear connector is then given by:

$$
P_{u}=2\left(A_{s 1}+A_{s 2}\right) \times \frac{f_{u}}{\sqrt{3}}+2 K_{c} \times A_{c} \times f_{c}
$$

where the factor 2 represents the two sides of the connector welded on the top flanges of the Ushaped steel beam; $A_{s 1}, A_{s 2}$ and $A_{c}$ are defined in Fig. 19, $f_{u}$ is the ultimate strength of the shear connector; $f_{c}$ is the compressive strength of concrete; and $K_{c}$ is a calibration factor on concrete strength due to local pressure effect. The calibration factor $K_{c}$ is defined by the following expression obtained from a regression analysis of the parametric study:

$$
K_{c}=19-38.1 \frac{h_{a}}{H_{c}}
$$


Table 6: Comparison of the ultimate loads given by proposed design equation against experimental and FEA results.

\begin{tabular}{|c|c|c|c|c|c|c|c|c|c|c|}
\hline$L_{\text {angle }}$ & $\begin{array}{c}f_{u} \\
(\mathrm{MPa})\end{array}$ & $\begin{array}{c}f_{c} \\
(\mathrm{MPa})\end{array}$ & $\begin{array}{l}H_{c} \\
\mathrm{~mm}\end{array}$ & $\begin{array}{l}L_{w} \\
\mathrm{~mm}\end{array}$ & $K_{c}$ & $\begin{array}{c}P_{s} \\
(\mathrm{kN})\end{array}$ & $\begin{array}{c}P_{c} \\
(\mathrm{kN})\end{array}$ & $\begin{array}{l}P_{u, t h} \\
(\mathrm{kN})\end{array}$ & $\begin{array}{c}P_{F E ; \exp } \\
(\mathrm{kN})\end{array}$ & $\frac{P_{u, t h}}{P_{u, F E}}$ \\
\hline L50a & 445 & 20.27 & 200 & 40 & 9.48 & 764 & 230 & 994.3 & 932.1 & 1.07 \\
\hline L50b & 445 & 21.29 & 200 & 40 & 9.48 & 764 & 242 & 1005.9 & 916.5 & 1.10 \\
\hline $\mathrm{L} 50 \mathrm{c}$ & 445 & 22.71 & 200 & 40 & 9.48 & 764 & 258 & 1022.1 & 975.9 & 1.05 \\
\hline L40 & 550 & 26.97 & 200 & 20 & 11.38 & 518 & 147 & 665.0 & 637.1 & 1.04 \\
\hline L30 & 360 & 42 & 200 & 30 & 13.29 & 250 & 301 & 551.2 & 582.3 & 0.95 \\
\hline L30 & 360 & 35 & 200 & 40 & 13.29 & 287 & 335 & 622.1 & 640.6 & 0.97 \\
\hline L30 & 445 & 35 & 200 & 40 & 13.29 & 355 & 335 & 689.9 & 709.4 & 0.97 \\
\hline L30 & 510 & 35 & 200 & 40 & 13.29 & 407 & 335 & 741.8 & 748.7 & 0.99 \\
\hline L30 & 550 & 35 & 200 & 40 & 13.29 & 439 & 335 & 773.7 & 755.7 & 1.02 \\
\hline L40 & 550 & 27 & 200 & 30 & 11.38 & 594 & 221 & 815.1 & 863.9 & 0.94 \\
\hline L40 & 550 & 27 & 200 & 40 & 11.38 & 670 & 295 & 965.1 & 900.5 & 1.07 \\
\hline L40 & 360 & 42 & 200 & 30 & 11.38 & 389 & 344 & 732.9 & 750.8 & 0.98 \\
\hline L40 & 550 & 35 & 200 & 30 & 11.38 & 594 & 287 & 880.7 & 921.4 & 0.96 \\
\hline L40 & 550 & 42 & 200 & 30 & 11.38 & 594 & 344 & 938.0 & 971.7 & 0.97 \\
\hline L50 & 360 & 42 & 200 & 30 & 9.48 & 556 & 358 & 913.7 & 953.5 & 0.96 \\
\hline L50 & 360 & 35 & 200 & 30 & 9.48 & 556 & 298 & 854.1 & 928.8 & 0.92 \\
\hline L50 & 360 & 27 & 200 & 30 & 9.48 & 556 & 230 & 785.8 & 869.6 & 0.90 \\
\hline L50 & 510 & 27 & 200 & 20 & 9.48 & 699 & 153 & 852.2 & 933.7 & 0.91 \\
\hline L50 & 510 & 35 & 200 & 20 & 9.48 & 699 & 199 & 897.7 & 979.2 & 0.92 \\
\hline L50 & 510 & 42 & 200 & 20 & 9.48 & 699 & 239 & 937.5 & 970.7 & 0.97 \\
\hline L50 & 445 & 27 & 200 & 40 & 9.48 & 764 & 307 & 1070.8 & 1040.0 & 1.03 \\
\hline L50 & 445 & 35 & 200 & 40 & 9.48 & 764 & 398 & 1161.8 & 1115.2 & 1.04 \\
\hline L50 & 445 & 42 & 200 & 40 & 9.48 & 764 & 478 & 1241.4 & 1190.4 & 1.04 \\
\hline L50 & 445 & 27 & 150 & 40 & 6.30 & 764 & 204 & 968.0 & 953.6 & 1.02 \\
\hline L50 & 445 & 35 & 150 & 40 & 6.30 & 764 & 265 & 1028.4 & 1059.0 & 0.97 \\
\hline L50 & 445 & 42 & 150 & 40 & 6.30 & 764 & 318 & 1081.4 & 1089.5 & 0.99 \\
\hline L50 & 445 & 27 & 120 & 40 & 3.13 & 764 & 101 & 865.1 & 850.6 & 1.02 \\
\hline L50 & 445 & 35 & 120 & 40 & 3.13 & 764 & 131 & 895.1 & 933.6 & 0.96 \\
\hline \multirow[t]{2}{*}{ L50 } & 445 & 42 & 120 & 40 & 3.13 & 764 & 158 & 921.3 & 977.5 & 0.94 \\
\hline & & & & & & & & & $\begin{array}{c}\text { moy } \\
\text { std }\end{array}$ & $\begin{array}{l}0.99 \\
0.05\end{array}$ \\
\hline
\end{tabular}

in which $h_{a}$ is the height of the L-shaped cross-section. Table 6 shows the comparison between the ultimate loads given by proposed design equation against FEA and experimental results. The 
first four values in the table represent experimental results. $P_{s}$ and $P_{c}$ represent the contribution of L-shaped shear connector and concrete to the shear capacity of the connector, respectively. It is shown that there is a good agreement between the results obtained from the proposed formulation and FEA results. It is worth mentioning that the case studies with the concrete strengths $10 \mathrm{MPa}$ and $60 \mathrm{MPa}$ have not been considered in the regression analysis. Indeed, such concrete classes are out of scope for usual buildings; moreover the results of the FE model should be confirmed by experimental testing with similar concrete resistance before being used.

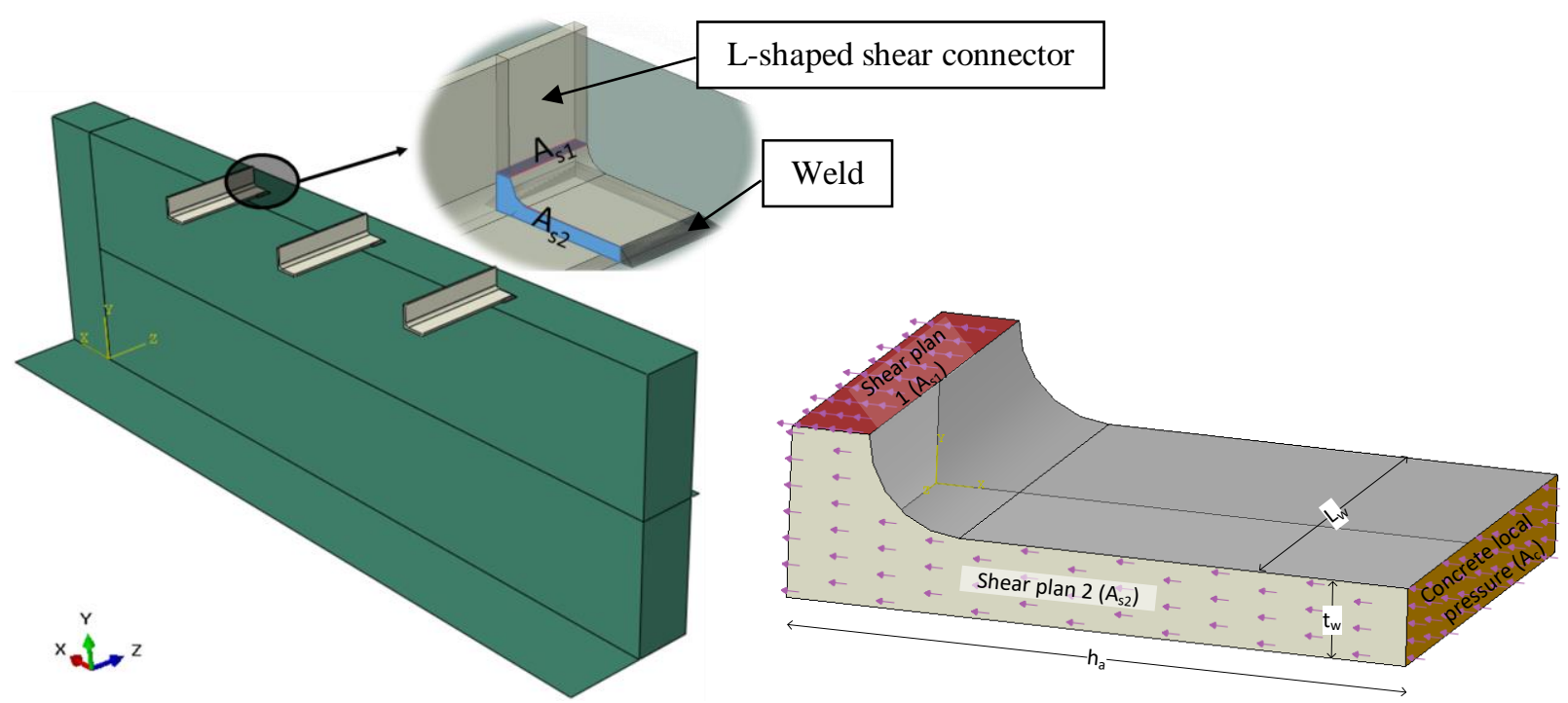

Figure 19: Shear failure plans and concrete local pressure zones.

\section{Conclusion}

Push-out experimental tests have been conducted on L-shaped and square bar shear connectors used in U-shaped steel-concrete hybrid beams. The experimental tests showed that:

- L-shaped shear connectors provided a ductile behavior while the square bar shear connector presented less ductility. The ductility of the former, similar to the one of classical studs, was associated with the plastification of the connectors before failure.

- The slip at load level descending to $90 \%$ of ultimate load is larger than $6 \mathrm{~mm}$, the minimal requirement of ductility to be considered as ductile following EC4 [24]. As square connectors did not meet this requirement, they were not considered as adequate and they have not been further investigated.

To identify the stress behavior of the L-shaped shear connector and of the surrounding concrete, a FE model was developed. It gave the key features in developing a new design equation for Lshaped shear connectors used in U-shaped steel-concrete hybrid beams. It showed that the shear 
connector resistance may be provided by two parts: concrete contribution and shear resistance of the connector. The latter is associated with the plastic deformation of connectors due to shear near the fillets between the angles of the cross-section and at the leg angle welded on the flange of steel beam. The former is due to the local pressure effect in the concrete block. To take into account this effect, a calibration factor obtained from a regression analysis has been introduced. It has been shown that the estimated ultimate loads are in good agreement with FEA and experimental results.

\section{References}

[1] H. Wright, H. Evans, P. Harding, The use of profiled steel sheeting in floor construction, Journal of Constructional Steel Research 7 (4) (1987) 279-295.

[2] M. L. Porter, C. E. Ekberg Jr, Design recommendations for steel deck floor slabs .

[3] J. Rackham, G. H. Couchman, S. Hicks, Composite slabs and beams using steel decking: best practice for design and construction, Metal Cladding \& Roofing Manufacturers Association in partnership with the Steel Construction Institute, 2009.

[4] D. J. Oehlers, Composite profiled beams, Journal of Structural Engineering 119 (4) (1993) 1085-1100.

[5] D. J. Oehlers, H. D. Wright, M. J. Burnet, Flexural strength of profiled beams, Journal of Structural Engineering 120 (2) (1994) 378-393.

[6] B. Uy, A. Bradford, Ductility of Profile Beams. Part I: Experimental Study, ASCE Journal of Structural Engineering .

[7] B. Uy, A. Bradford, Ductility of Profile Beams. Part II: Analytical Study, ASCE Journal of Structural Engineering .

[8] Y. Liu, L. Guo, B. Qu, S. Zhang, Experimental investigation on the flexural behavior of steel-concrete composite beams with U-shaped steel girders and angle connectors, Engineering Structures 131 (2017) 492-502.

[9] I. M. Viest, Investigation of stud shear connectors for composite concrete-steel T-beams, Journal of the american concrete institute 27 (8) (1956) 875-891.

[10] J. Chinn, Pushout Tests on Lightweight Composite Slabs, AISC Engineering Journal 2 (4) (1965) 129-134.

[11] I. B. Valente, P. J. Cruz, Experimental analysis of shear connection between steel and lightweight concrete, Journal of Constructional Steel Research 65 (10) (2009) 1954-1963.

[12] D. Lam, E. El-Lobody, Behavior of headed stud shear connectors in composite beam, Journal of Structural Engineering 131 (1) (2005) 96-107.

[13] E. Ellobody, B. Young, Performance of shear connection in composite beams with profiled steel sheeting, Journal of Constructional Steel Research 62 (7) (2006) 682-694.

[14] H. T. Nguyen, S. E. Kim, Finite element modeling of push-out tests for large stud shear connectors, Journal of Constructional Steel Research 65 (10) (2009) 1909-1920.

[15] H. Abe, T. Hosaka, Flexible shear connectors for railway composite girder bridges, Composite construction in steel and concrete IV (2002) 71-80. 
[16] S. Maleki, S. Bagheri, Behavior of channel shear connectors, Part I: Experimental study, Journal of Constructional Steel Research 64 (12) (2008) 1333-1340.

[17] S. Maleki, S. Bagheri, Behavior of channel shear connectors, Part II: Analytical study, Journal of Constructional Steel Research 64 (12) (2008) 1341-1348.

[18] A. Pashan, M. Hosain, New design equations for channel shear connectors in composite beams, Canadian Journal of Civil Engineering 36 (9) (2009) 1435-1443.

[19] E. Baran, C. Topkaya, An experimental study on channel type shear connectors, Journal of Constructional Steel Research 74 (2012) 108-117.

[20] M. Shariati, N. R. Sulong, M. Suhatril, A. Shariati, M. A. Khanouki, H. Sinaei, Behaviour of C-shaped angle shear connectors under monotonic and fully reversed cyclic loading: an experimental study, Materials \& Design 41 (2012) 67-73.

[21] M. Shariati, N. R. Sulong, M. Suhatril, A. Shariati, M. A. Khanouki, H. Sinaei, Comparison of behaviour between channel and angle shear connectors under monotonic and fully reversed cyclic loading, Construction and Building Materials 38 (2013) 582-593.

[22] R. Soty, H. Shima, Formulation for shear force-relative displacement relationship of L-shape shear connector in steel-concrete composite structures, Engineering Structures 46 (2013) 581-592.

[23] A. Shariati, M. Shariati, N. R. Sulong, M. Suhatril, M. A. Khanouki, M. Mahoutian, Experimental assessment of angle shear connectors under monotonic and fully reversed cyclic loading in high strength concrete, Construction and Building Materials 52 (2014) 276-283.

[24] EN1994-1-1, Eurocode 4: design of composite steel and concrete structures-Part 1.1: General rules and rules for buildings, Brussels: European Committee for Standardization .

[25] D. Lowe, R. Das, C. Clifton, Characterization of the Splitting Behavior of Steel-concrete Composite Beams with Shear Stud Connection, Procedia Materials Science 3 (2014) 2174-2179.

[26] C. Topkaya, J. A. Yura, E. B. Williamson, Composite shear stud strength at early concrete ages, Journal of Structural Engineering 130 (6) (2004) 952-960.

[27] A. Documentation, U. Manual, Version 6.10, Dassault Systemes .

[28] B. Alfarah, F. López-Almansa, S. Oller, New methodology for calculating damage variables evolution in Plastic Damage Model for RC structures, Engineering Structures 132 (2017) 70-86.

[29] EN 1992-1-1, Eurocode 2: Design of Concrete Structures: Part 1-1: General Rules and Rules for Buildings, Brussels: European Committee for Standardization .

[30] W. B. Krätzig, R. Pölling, An elasto-plastic damage model for reinforced concrete with minimum number of material parameters, Computers \& structures 82 (15) (2004) 1201-1215.

[31] J. Oliver, A consistent characteristic length for smeared cracking models, International Journal for Numerical Methods in Engineering 28 (2) (1989) 461-474.

[32] D. A. Hordijk, Tensile and tensile fatigue behaviour of concrete; experiments, modelling and analyses, Heron 37 (1) (1992) 3-79. 